\title{
Run Aground: Kit Fine’s Critique of Truthmaker Theory
}

\author{
Forthcoming in Philosophical Quarterly \\ Jamin Asay \\ University of Hong Kong \\ asay@hku.hk
}

\begin{abstract}
Kit Fine, the leading proponent of the metaphysical project of grounding theory, has offered a number of potentially devastating objections to truthmaker theory, the branch of metaphysics dedicated to exploring the ontological grounds for truths. In this paper I show what presuppositions about truthmaker theory Fine's objections are based upon, and why they are false. I discuss four objections that Fine raises, and demonstrate how truthmaker theorists may respond to them. I then showcase the positive contribution that truthmaker theory can make to metaphysics, including its ability to speak to a core metaphysical topic (the ontological grounds for truths) that Fine's approach to grounding must ultimately remain silent on. I conclude by exploring what I take to be the best option when it comes to understanding how truthmaking and grounding fit together.
\end{abstract}

'The truth-maker theorist is like someone who, faced with the problem of fitting a round peg into a round hole, first makes the round peg square and then attempts to solve the problem of fitting a square peg into a round hole.'

Kit Fine, ‘Guide to Ground'

\section{Introduction}

In the epigraph above, Kit Fine succinctly presents his assessment of truthmaker theory (2012: 45). The passage forms part of his indictment of the truthmaking project, which he sees as a competitor to his theory of grounding. His critique is concise, comprehensive, and devastating. It is, however, unsuccessful. Fine's presentation of truthmaker theory is both inaccurate and 
uncharitable; its rhetoric far outstrips the strength of its objections. As a result, his critique provides no defense of his own work on grounding. The relationship between the theory of grounding and the theory of truthmaking has yet to be sufficiently explored; both topics are relative newcomers to metaphysics, and how they do and do not intersect is a live topic. Given his brusque and dismissive discussion of truthmaking, readers attracted to Fine's work on grounding are offered a very simple view about the relationship: truthmaker theorists and grounding theorists aim at the same set of objectives, and while the latter are succeeding and developing sophisticated theories that have implications all across philosophy, the former are inexorably failing. I offer this paper as a corrective to Fine's attempted refutation, and to plead for more constructive investigation into the relationship between truthmaking and grounding.

I begin by discussing the central points of Fine's presentation of truthmaker theory. The four objections he offers turn on those key theses, and seeing what is wrong with Fine's critique depends on seeing how his presentation of truthmaker theory is flawed. While my most immediate objective is to respond to Fine's very sharp criticisms, along the way I shall present a more positive perspective on truthmaker theory, how it is best understood, and how it can work in conjunction with grounding theory, not in opposition to it. I present an account of truthmaking that speaks to a crucial theoretical need that grounding theory—as Fine construes it—must remain silent on. I conclude by considering what I take to be the most promising perspective on how truthmaking and grounding relate to one another.

\section{Fine on Truthmaker Theory}

Fine presents truthmaker theory as being a 'close cousin' of grounding (2012: 43). To substantiate this claim, he describes both theories as being attempts to understand the 'general phenomena of what accounts for what' (ibid.). To use some classic examples, what accounts for the existence of the singleton \{Mount Hood\} is Mount Hood itself: the singleton exists because the mountain does. According to one of Euthyphro's attempted definitions, what accounts for an action's being pious is its being loved by all the gods (Plato 1997: 9; 9e1-10a2). And what accounts for the truth of the proposition $<$ Copper conducts electricity $>$ is its truthmaker, whatever it turns out to be. According to Fine, what grounding and truthmaking theorists aim to understand is the nature and structure of these various accounting claims. Hence, Fine's first core thesis about truthmaking is the following: 
(1) Truthmaker theory (like grounding theory) aims to offer an account of the general phenomena of what accounts for what.

Despite this shared goal, Fine quickly notices a major difference in approach between the two views. He correctly points out that the truthmaking relation is usually understood as obtaining between an existing item in the world and something truth-bearing. For example, truthmaking holds between the mountain Mount Hood and the proposition < Mount Hood exists>. Because the object exists, the proposition in question is true. Truthmaking is thus a cross-categorial relation: the entities on either side of the relation can belong to distinct ontological categories. Grounding, by contrast, should be understood as holding between entities of the same type. Though he prefers not to take a decisive stand, Fine announces his preference for taking grounding to hold between facts, not propositions. Note, as will be important later, that Fine uses 'fact' to refer to 'worldly entities' that are distinct from true propositions (2012: 43).

As for the relation itself, Fine maintains that truthmaking is a purely modal notion, defined in terms of metaphysical necessitation: some object $x$ is a truthmaker for some representation $y$ if it's necessary that if $x$ exists, then $y$ is true. Hence:

(2) The truthmaking relation is explicated modally: necessitation is sufficient for truthmaking.

With this account of truthmaking, the truthmaker theorist hopes to identify which entities in reality are responsible for the truth of everything that is true. Because it's necessary that if Socrates exists, then $<$ There are humans $>$ is true (assuming that Socrates is essentially human), Socrates is a truthmaker for <There are humans>. Those familiar with Fine's work (e.g. Fine 1994) will recall that he thinks notions like dependence and essence cannot be understood in purely modal terms. \{Mount Hood\} depends on Mount Hood, but not vice versa, though it's necessary that if one of them exists, so too does the other. Grounding, too, cannot be accounted for in purely modal terms. So here again we see an alleged difference between truthmaker theory and grounding.

There are a number of other claims that Fine makes concerning truthmaking, and I shall come to them in due course, but (1) and (2) are the cornerstones of his overall critique. As will emerge in the next section, neither (1) nor (2) is true; seeing why they are false is key to undermining Fine's critique of truthmaking. 


\section{Fine Against Truthmaker Theory}

Fine presents four objections to truthmaker theory, all of which depend in some way on (1) or (2). I address each of them in turn.

First, Fine challenges truthmaker theorists' view as to what is able to be grounded (2012: 43). Hence:

(A) Truthmaker theory has an overly restricted and arbitrary conception of what is grounded.

Fine's idea is that truthmaker theorists, like himself and other grounding theorists, are interested in understanding the general nature of grounding - this, recall, is thesis (1). Truthmaker theorists maintain that it is truths that are made true by existing objects. Presented in terms of grounding, then, truthmaker theorists maintain that truths, and not anything else, are what get grounded. This restriction is arbitrary, according to Fine, as other things stand in need of grounds as well.

Crucial to objection (A) is the presupposition that truthmaker theory is an attempt to give an exhaustive account of the various phenomena of grounding. If truthmaker theory were instead focused on exploring just one corner of the grounding terrain, then the objection would fall flat. For what is not at all arbitrary is the claim that the only things that are made true are truths. What is contentious is to say that the only things that are grounded are truths. This latter claim is what Fine finds objectionable about truthmaker theory, and it reveals that he believes that truthmaker theorists take grounding to be fully accounted for by truthmaking.

Though it is clear that Fine is making this assumption, there is no textual basis for it. There is simply no indication that truthmaker theorists are aiming to explain every sort of fact concerning something accounting for something else. It should be clear from the literature about truthmaking that the field is concerned with specifying the best account of ontology that follows from one's commitments as to what is true. Truthmaker theory begins with the idea that when a proposition (or other kind of truth-bearer) is true, its truth depends on reality. The requisite attitude about ontology that accompanies that truth is then explored. Such a project has no pretensions of giving an exhaustive account of all kinds of accounting, or all kinds of grounding. In fact, it's perfectly open (though not required) for a truthmaker theorist to accept truthmaking as being a species of grounding, but not identical with grounding itself. (I explore this option in detail below.) For example, one might take the truthmaking that obtains between Socrates and $<$ There are humans $>$ to be one kind of grounding, but distinct from the non-truthmaking grounding that holds between 
Socrates and \{Socrates\}. For objection (A) to have any bite, (1) must be true. Fine offers no textual evidence that any truthmaker theorist has the ambitions of offering a comprehensive theory of ground. This is unsurprising, because there is no such evidence.

A natural retort for Fine to make here is to challenge the legitimacy of any truthmaker theory that rejects (1). "Modest" truthmaker theory that concerns itself with only one aspect of grounding still fails to be a worthwhile metaphysical enterprise, either because it can be subsumed under the general theory of grounding, or because it fails to have the same scope as the theory of grounding. The problem with these responses is that they are premature, and set up truthmaking and grounding as antecedently oppositionary forces. Should truthmaking turn out to be a kind of grounding that is relevant to grounding theorists, then the latter have much to learn from it (cf. Griffith 2014: 212-3). Truthmaker theorists have well-developed theories and discussions of problematic corners of metaphysics that can provide a wealth of insight into how grounding works in particular cases. Should truthmaking turn out not to be a form of grounding, it may indeed have a more limited scope than does grounding theory. But that is no objection to truthmaker theory unless one thought that its having limited scope was some sort of fatal flaw. Fine may well believe that truthmaker theory is of little interest because it is not intended to speak to the broader concerns of grounding, but this attitude is too hasty. In the next section, I'll speak to this dismissive attitude that likely fuels the abrupt attempt at refutation that Fine offers. Fine presents grounding theory and truthmaker theory as two sides of a turf war, with one party winning handily. In reality, this is a turf war where one party is quite conspicuously absent.

In presenting objection (A), Fine also reveals a further misunderstanding about the truthmaking project. In addressing why truthmaker theory has unwisely limited its scope, he writes: 'For whenever we consider the question of what makes the representation that $\mathrm{P}$ true, there will also arise the question of what, if anything, makes it the case that P' (2012: 43). Fine believes that truthmaker theorists concern themselves with the truthmakers for truths of the form $<<p\rangle$ is true $>$, but not truths of the form $\langle p\rangle$. As a result, they once again needlessly limit their focus. This is tantamount to saying that truthmaker theorists are concerned exclusively with the truth of true truth-ascriptions in particular, and not truths in general. But again, this claim is baseless. Truthmaker theorists are just as interested in the truthmakers for $<$ Snow is white $>$ as they are in the truthmakers for $<<$ Snow is white $>$ is true $>$. On my view, at least, the truthmakers are just the same. (See also Armstrong 1997: 119.) Suppose some object $x$ is the truthmaker for $<$ Snow is white $>$. Then $x$ will also be the truthmaker for each "semantically ascended" claim as well, such as $<<<$ Snow is white $>$ is true $>$ is true $>$ and all the infinitely many others. There is absolutely no 
reason for reading truthmaker theorists as ignoring the truthmakers for the "ground level" propositions.

Fine does follow up his mistaken reading of the literature with a correct observation about representational truth-bearers (such as sentences): 'it might well be thought that the question concerning the representation will always divide into two parts, one concerning the ground for what it is for the representation that $\mathrm{P}$ to represent $\mathrm{P}$ and the other having nothing to do with representations as such, but concerning the ground for P' (2012: 43). Indeed. Why Fine finds an objection to truthmaker theory here is left unexplained. Take the English sentence 'Socrates is human'. As a matter of contingent fact, 'Socrates is human' expresses the proposition $<$ Socrates is human>. So we can ask two separate truthmaking questions: What makes $<$ Socrates is human $>$ true, and what makes <'Socrates is human' expresses $<$ Socrates is human $>>$ true? Socrates himself is commonly taken to be the truthmaker for the former; to my knowledge, the truthmaker in the latter case has not been explicitly discussed as such, but presumably involves the social conventions that give content to the English language. Regardless of one's specific view about the truthmakers here, the important point to notice is that the questions Fine raises are just ordinary truthmaking questions; they do nothing to support his contention that truthmaker theorists are myopic in their theoretical concerns.

To summarize, Fine's first objection is that the scope of what is grounded in truthmaker theory is needlessly limited. The objection turns on a misappropriation of truthmaker theory: Fine sets it up for failure by conflating its theoretical ambitions with his own. Moving on, Fine also has a problem with truthmaker theory's posited grounds. Hence his second objection:

(B) Truthmaker theory has (i) an overly and arbitrarily restricted and (ii) independently problematic conception of what grounds.

Just as it was too limiting to say that only truths are grounded, Fine believes it's too limiting to say that only existing things can ground. Furthermore, using existing objects to ground truths is, Fine believes, 'somewhat suspect' (2012: 44).

As for the first charge, Fine writes that, according to truthmaker theory, 'grounds should take the form of existential attributions; it is always the existence of something that properly accounts for the truth of the representation' (2012: 43-4). This is too restrictive, for grounds should also be able to be relational: 'Perhaps it can lie in something relational, $a$ standing in the relation $\mathrm{R}$ to $b$, or the negation of something relational, $a$ not standing in relation $\mathrm{R}$ to $b$, or in something of some other form' (2012: 44). 
In response, first a clarification. For truthmaker theorists, it is not existential attributions that are truthmakers, or even the existence of something that is a truthmaker. Objects themselves are the grounds. It is Socrates that is the grounds for $<$ Socrates is human $>$, not any sentence that attributes existence to Socrates, the proposition <Socrates exists>, or "Socrates's existence", whatever that term might refer to. Once it's clear that objects themselves are the grounds, it's easy to see why truthmaker theory sets no limits on what can serve as a ground. On my view, literally everything is a truthmaker, and so everything performs a grounding role. ${ }^{1}$ For any object $x, x$ is a truthmaker for $<x$ exists $>$. Given that everything in reality is a truthmaker, truthmaker theory cannot be charged with being too restrictive about what can count as a truthmaker.

Now, Fine does attempt to specify the possibility that he thinks truthmaker theorists are ignoring. In addition to looking for something existing, we should also attend to something relational. The problem with this objection is its obscurity. What does Fine refer to by 'something relational'? If it's a something, i.e. something that exists, then he has offered a false dichotomy. A thing that is relational is still a thing. Fine uses the expression ' $a$ standing in the relation $\mathrm{R}$ to $b$ '. One option for understanding this expression is as referring to something like an Armstrongian state of affairs, which is a non-mereological composite of universals and particulars (Armstrong 1997). If $\mathrm{R}$ is a relational universal, and $a$ and $b$ are particulars that instantiate it, then there exists a state of affairs that we might name with Fine's expression, and which will be a truthmaker for $<a$ stands in $\mathrm{R}$ to $b>$. Thus, relational things can be truthmakers (and are, in the view of the most developed truthmaker theory available), contrary to Fine's claim.

But Fine also claims that his things that are relational can be negated. This highly suggests that his 'something relational' is actually something propositional, since negations attach to propositions (or something expressing them). ${ }^{2}$ In that case, Fine's proposed grounds aren't suited to the truthmaker theorist's purpose. For truthmaker theorists are interested in what it is in reality that grounds the truth in question. To point to another truth might serve various explanatory purposes, but it doesn't answer the ontological question that the truthmaker theorist is asking. Suppose, for example, that $<$ Giving to charity $A$ is better than giving to charity $B>$ is true. If utilitarianism is true, then we might explain this claim by pointing to "something relational", i.e. the fact that giving to charity A produces more net happiness than does giving to charity $\mathrm{B}$. In effect, we are explaining one relational truth (involving 'better than') in terms of another (involving

\footnotetext{
${ }^{1}$ Not everyone agrees, such as those like Rettler (2016) who require truthmakers to be fundamental entities.

${ }^{2}$ Furthermore, the fact that he claims that standard truthmakers are existential attributions suggests that he thinks all truthmakers are propositional in nature, which is another case of Fine reading his own grounding theory into truthmaking.
} 
'produces more net happiness than'). If one answers a truthmaking query by pointing to another truth, then the question arises as to what the truthmaker is for that further truth. Until we get an ontological answer, we haven't settled the initial truthmaking inquiry. All told, Fine's proposed alternative to existing truthmakers is either no alternative at all, or one that simply pushes the question back a step.

One way of making sense of Fine's objection is to read him as interpreting truthmaker theory in a way suggested by Ross Cameron (forthcoming). On Cameron's proposal, truthmaking is just a kind of grounding. True propositions ground other true propositions, though some true propositions have no grounds and thus are brutely true. What it is for an object $x$ to "make true" a proposition $\langle p\rangle$ is for $\langle p\rangle$ to be grounded by $\langle x$ exists $\rangle$. Thus, for Cameron all the brutely true propositions are existential. His idea is that what is distinctive to truthmaker theory is that it accepts only existential propositions as being brute: all other truths are ultimately grounded in the existential truths. If Fine interprets truthmaker theory in this way, then his complaint might be: why can't non-existential propositions such as relational propositions or negated propositions belong to the set of brute truths? Cameron has an answer to Fine's question. Theoretical economy demands that, ceteris paribus, the class of brute truths be as simple as possible, quantitatively and qualitatively. That is, one should aim for as few brute truths as possible, and as few kinds of brute truths as possible. Cameron's truthmaker theorist has one simple kind of truth in its fundamental set: existential truths. Fine's proposed alternative complicates and diversifies the makeup of the fundamental set, which puts his view at a comparative disadvantage.

Fine might be thinking about truthmaking in a way that matches Cameron's proposal, but that's not obvious. If he were, then he would think that truthmaking is not cross-categorial, since truthmaking for Cameron is just a relation of grounding between true propositions. Furthermore, Cameron's proposal is highly idiosyncratic, in that it does not represent the familiar approaches to truthmaking which Fine intends to target. (As I argue below, Cameron's proposal is antithetical to the basic motivation behind truthmaking.) Hence, if Fine's target is just Cameron's unique take on truthmaking, then not only does he fail to accomplish his goal of undermining truthmaking in general, he also fails to undermine even Cameron's perspective. For Fine doesn't go beyond raising a question for which Cameron has a ready answer.

Hence, Fine has no grounds for thinking that truthmakers are too limited in scope. Truthmakers are found in every last corner of the universe. But recall that Fine also suspects that citing existing items as grounds is itself problematic. He writes: 'For it is much more natural to suppose that it is because $\mathrm{P}$ (e.g. it is raining) that the fact that $\mathrm{P}$ exists, rather than the other way round. One can only conjecture as to why truth-maker theorists might have built such an 
implausible view into their conception of truth-making' (2012: 44). From this passage, it appears that Fine believes that truthmaker theorists are committed to the claim that, for any proposition $<p>, p$ because the fact that $p$ exists. This commitment generates an extravagant ontological commitment—a worldly fact for every truth—that has no textual basis; Fine certainly provides no evidence that anyone in the truthmaking literature accepts this view. ${ }^{3}$ That Fine is misreading truthmaker theory is quite obvious, given that truthmaker theory-from its very inception in Russell's (1918) logical atomism—has attempted to do without a one-one correspondence between truth and fact. From some proposition < $p$ >'s being true, we cannot simply infer that there is an entity called 'the fact that $p$ '. One might go so far as to say that this is the whole point of truthmaker theory: trying to find a sensible and economical ontology to ground all the various kinds of truths. ${ }^{4}$

Besides, facts are no antecedent commitment of truthmaker theory. Plenty of approaches to truthmaker theory (e.g. Mulligan, Simons, and Smith 1984) eschew them. For those who do adopt facts (or states of affairs, as Armstrong calls them), there is no way of reading what facts there are off of the truths in question. Armstrong, for example, would maintain that the truthmaker for the essential predication $<$ Socrates is human $>$ is not a fact at all, but Socrates himself. An accidental predication such as < Socrates is a philosopher $>$ does, for Armstrong, have a state of affairs for its truthmaker, but what that state of affairs is is not obvious. States of affairs are composed in part by universals, and there is no universal corresponding to every predicate. Which universals there are is determined by empirical study, and it's highly unlikely that being a philosopher is among them. (Universals are typically associated with the most "natural" properties, the ones that have causal powers, account for genuine resemblances, and figure into scientific theories.) So 'the fact that Socrates is a philosopher' has no referent on Armstrong's view, if it's intended to pick out a state of affairs composed by Socrates and a universal being a philosopher.

Fine also asserts that he believes that for any proposition $\langle p\rangle$, the fact that $p$ exists because $p$. Given that Fine has made it clear that he interprets 'fact' to mean something "worldly" (and not simply 'true proposition'), this is a substantive ontological commitment on his part. For every true proposition, there is in addition some extra entity named in terms of that proposition. Truthmaker theorists would be interested to hear the justification for such a commitment. Perhaps Fine has some view of what he calls 'facts' on which it is acceptable to claim that they are derivative of true propositions, but he cannot in good conscience have in mind the facts of truthmaker theorists like

\footnotetext{
${ }^{3}$ To my knowledge, only Fiocco (2013) has defended such a view.

${ }^{4}$ Here are Mulligan, Simons, and Smith, one of the few sources cited by Fine: 'Provided we can account for the truth and falsehood of atomic sentences, we can dispense with special truth-makers for, e.g., negative, conjunctive, disjunctive, and identity sentences' (1984: 289).
} 
Armstrong while claiming that they are derivative existences that exist only because their corresponding claims are true. Though I have no interest in adjudicating which metaphysical claims are more "natural" than others, it is important to emphasize that the truthmaker theorist's claim here is only that propositions are true in virtue of their worldly truthmakers. This idea has long motivated truthmaker theory, ever since Aristotle (1995: 11-2; 14b14-22), and I would be surprised if Fine denies it. But if he doesn't, then it's unclear what the implausible thesis is that truthmaker theorists supposedly adopt.

Fine's third criticism is the allegation that truthmaker theory cannot accommodate the phenomenon of intermediate grounding:

(C) Truthmaker theory cannot account for the hierarchy of grounding claims.

He suggests, for example, that normative facts are grounded in natural facts, which in turn are grounded in physical facts, which are grounded in microphysical facts. In the truthmaking paradigm, by contrast, some given normative fact is assigned a truthmaker, and there ends the story. Truthmaking takes us from truth to existence, not another truth. Hence, the cross-categorial nature of truthmaking prevents the formation of the grounding chains that interest Fine.

The most immediate response to objection $(\mathrm{C})$ is again to explain how it falsely relies on (1), the idea that truthmaker theory is an attempt to capture all the phenomena related to grounding. But since truthmaker theory aims to tell at most only part of the grounding story, its inattention to the hierarchy of grounding claims is no objection. (C), like (A), fails due to Fine's assigning his own theoretical ambitions to truthmaker theory. Still, even though truthmaker theory doesn't aim to capture the various sorts of intermediate grounding claims in which Fine believes, it would be a problem if it were somehow opposed to such claims, or were forced to deny them. But there is no reason to think that truthmaker theorists cannot accept intermediate grounding claims. To say that a set of truths stand in one set of grounding relations with each other is consistent with saying that they stand in a different grounding relation to various worldly entities.

To better see why truthmaker theory provides no obstacle to thinking about the kinds of hierarchical claims that interest Fine, consider a specific example. Take a metaethical view that appeals to ideal observers (e.g. Milo 1995). On such a view, moral goodness might be explicated as the property belonging to those actions that an ideal set of observers, in ideal circumstances, would recommend pursuing. With this account in hand, one might analyze a moral judgment such as $<$ Giving to charity $A$ is morally good $>$ as $<$ An ideal set of observers in ideal circumstances would recommend giving to charity $\mathrm{A}>$. What we have here is an analysis (or reduction, perhaps) 
of a moral judgment provided by a non-moral judgment. In giving this analysis, there is no presumption that the analyzing judgment is metaphysical bedrock, or somehow conceptually primitive. With respect to metaethics, the job might be finished: the ideal observer theorists have provided an analysis of morality in non-moral terms (though of course it would behoove them to spell out what they have in mind by ideal observers and conditions, so as to fend off potential accusations of circularity). It would be ridiculous to object to them with the charge that they haven't also analyzed the relevant non-moral judgements as well. But this is just the sort of charge Fine brings to truthmaker theorists: though they have provided an account of the ontological requirements for any given truth, they have failed to specify what other truths are conceptually or metaphysically related to the initial truth.

There are many important questions concerning the relationship alleged to hold between $<$ Giving to charity A is morally good $>$ and $<$ An ideal set of observers in ideal circumstances would recommend giving to charity $A>$. Understanding the relationship speaks to core metaphilosophical issues about what conceptual analysis (and, moreover, philosophy) is all about. Truthmaker theorists need only claim that the relationship is not one of truthmaking. It couldn't be. The existence of one of these propositions doesn't guarantee the truth of the other. (They are contingently true, after all.) But that is not to say that there aren't absolutely central questions here about the nature of morality. Not all important metaphysical and conceptual claims are truthmaking claims.

If truthmaking doesn't take itself to be offering the sorts of conceptual analyses often of interest to metaethics and other philosophical views, does that mean it has nothing to contribute to these concerns? Not at all. Truthmaker theorists explore what sort of ontology is required in order for claims to be true. If a purported analysis takes us from $\langle p\rangle$ to $\langle q\rangle$, the proposal may be illuminating or explanatory in various ways, but it's not yet ontologically revealing. Perhaps in order for $\langle p\rangle$ to be true, $\langle q\rangle$ must be true. But the truthmaker theorist still wants to know what makes $\langle p\rangle$ true: what ontological worldview does $\langle p\rangle$ commit us to? Being directed to $\langle q\rangle$ doesn't answer that question, but it could be helpful. For the question of $<q>$ 's truthmaker might be much more tractable. If it is, then we also have the answer (or at least the start of an answer) to what makes $\langle p\rangle$ true. For example, those seeking out naturalistic analyses of moral judgments might do so in part because telling the ontological story for a set of naturalistic judgments might be less controversial and more parsimonious than non-naturalistic approaches.

Many questions remain. Even if $\langle p\rangle$ is best analyzed by $\langle q\rangle$, it might not follow that $\langle p\rangle$ is grounded by $\langle q\rangle$; perhaps analytical and ontological dependence do not always line up. Still, regardless of their relative priority, if $\langle p\rangle$ and $\langle q\rangle$ are mutually entailing, then many truthmaker 
theorists would accept that they have the same truthmakers (at least in a significant number of cases). That is because many accept an entailment principle, such that any truthmaker for a proposition is also a truthmaker for anything entailed by the proposition (Armstrong 2004: 10-2). Such principles are contentious (a matter that will arise again below), as their plausibility depends on how entailment is understood. But once properly defended, their implications can be brought to bear on the relevant hierarchies of truths that grounding theorists develop. What ultimately matters is that when it comes to the truths of various domains, theorists of grounding and truthmaking can cooperate with each other and with the theorists within those domains to produce a full picture of the metaphysical and ontological structure of the areas in question. There is no need to see grounding theorists and truthmaker theorists as working in competition with, or opposition to each other.

One reason this sort of inquiry is important is that it helps us understand what is at stake in traditional debates over the nature of, say, moral realism. If ideal observer theorists remain silent on what makes true their analyzing judgments, then it's unclear whether or not they've avoided the ontological posits of moral realism. The familiar positions in the moral realism debate can be understood in terms of what they take the truthmakers to be for moral judgments (here I follow Asay 2013). Ideal observer theorists might be right to direct our attention toward various counterfactual conditionals about ideal observers, but they still need to consider what makes those counterfactuals true. Only after they show that they can circumvent the realists' ontological posits have they demonstrated the anti-realist credentials of their view (if indeed that is their intention).

In sum, the various claims belonging to Fine's hierarchy are best understood as expressing various relationships of metaphysical and/or conceptual priority between judgments of different types. Though these relationships are not truthmaking relationships, the truthmaking relation might track them: that is, if $\langle p\rangle$ is analyzed by $\langle q\rangle$, then although $\langle q\rangle$ itself isn't the truthmaker for $\langle p\rangle$, there is a plausible case to be made that whatever makes $\langle q\rangle$ true also makes $\langle p\rangle$ true. (How generally this principle applies will depend on individual cases, and is a matter I cannot explore at the moment.) As a result, the interests of grounding theorists and truthmaking theorists are if anything complementary; they work together in order to offer a full perspective on the metaphysical-conceptual-ontological nature of the world and how its pieces fit together.

Consider now the final objection Fine makes to truthmaker theory:

(D) The truthmaking relation is too liberal, and leads to rampant triviality about truthmaking. 
This objection crucially relies on (2), Fine's claim that metaphysical necessitation is sufficient for truthmaking. Given (2), as Fine points out, it follows that every existing object is a truthmaker for every necessary truth. For it's necessary that if I exist, then $<7+5=12>$ is true. Other cases arise when there are necessary connections between contingently existing objects. For example, the existence of $\{$ Mount Hood\} necessitates the truth of $<$ Mount Hood exists $>$, even though the proposition isn't about the singleton containing Mount Hood.

Further trivialities arise when we pair truthmaker theory with what Fine calls 'certain quite plausible metaphysical views' (2012: 45). 'One might well think', he writes, 'that for any truth p, the fact that $\mathrm{p}$ will be a truth-maker for any true proposition p' (ibid.). The problem here, presumably, is that the task of finding a truthmaker is always moments away, and thus far too easily accomplished. What is the truthmaker for $<$ Slavery is wrong $>$ ? The fact that slavery is wrong. What is the truthmaker for $<7+5=12>$ ? The fact that $7+5=12$. Any ontological analysis that is accomplished so simply must be worthless. Finally, Fine points out that if we take the world to exist and not be able to exist without being the way it is, then the world itself provides a truthmaker for every last truth. If the world is essentially the way it is (in other words, had reality been different, a different world would have existed, not the actual one), its existence guarantees the truth of everything that is in fact true.

In response, the most important fact to point out is that (2) is blatantly false, and recognized as such by all leading truthmaker theorists. At least since Restall (1996) discussed cases of this sort, most truthmaker theorists are united in thinking that necessitation is necessary but not sufficient for truthmaking (e.g. Armstrong 2004: 17, a book which Fine cites). Truthmaker theorists have come around to the view that truthmaking is a hyperintensional relation, such that it cannot be given a full modal explication. Here we have a commonality, not a difference, between truthmaking and grounding. Fine's contention that truthmaking is 'usually' explicated as in (2) is a baseless empirical claim. Just exactly what else needs to be added to necessitation to produce truthmaking is a matter of much debate. The existence of such discussion (see, for example, Lowe 2007, Merricks 2007, and Schaffer 2010) only further reveals Fine's misreading of the literature.

Rather than being saddled with trivial truthmakers for necessary truths, theories of truthmaking are intentionally developed to avoid such consequences (much as Fine's account of essence is developed to avoid saddling an object's essence with all necessary properties of that object). As for Fine's other triviality objections, they turn on either irresponsible ontological postulations or misunderstandings of the truthmaking enterprise. The allegation that 'the fact that $p^{\prime}$ can always be cited as a truthmaker for $\langle p\rangle$ relies not on an 'innocuous' metaphysical view, as Fine has it (2012: 46), but upon an attitude of utter ontological frivolity. As noted already, those 
who take 'fact' to name existing components of reality (such as Armstrong regarding states of affairs) do not posit one fact for every truth. Such rampant positing is ontological excess, and has no place in serious metaphysics. Considerations of parsimony demand that entities are posited because they play a crucial theoretical role. Fine provides no such role to justify his fact proliferation. Of course, there is a sense of 'fact' for which there is a fact for every truth. This is the sense of 'fact' that means 'true proposition'. But on that reading, facts are not fit to be truthmakers, for their mere existence does not guarantee their truth. ${ }^{5}$ The fact (i.e. true proposition) $<$ Plato revered Socrates $>$ does not make it true that Plato revered Socrates; the proposition could have existed but been false. What makes the proposition true is some cluster of mental states in Plato's head. Fine wants facts both ways at the same time: he wants there to be one for every truth, but also for them to have truthmaking relevance.

Finally, what of Fine's concern that the world (if essentially the way it actually is) is a truthmaker for every truth? He claims that this view 'cannot legitimately be regarded as enabling us to find a truth-maker for every truth' (2012: 46). But it is just that: a claim. Fine asserts it without argument, so it's unclear why he sees a problem here. Truthmaker theorists often don't. Such a view is the cornerstone of Cameron's (2008a) attempt to find truthmakers for negative existentials. Armstrong, for his part, explicitly embraces this consequence. He calls the world the most promiscuous' and 'the least discerning truthmaker of them all' (2004: 19). Yet to say that the world is a truthmaker for every truth is not to say that it is the only truthmaker, or the most minimal truthmaker. ${ }^{6}$ It is no contention of truthmaker theory that truths have only a single truthmaker, and so the fact that at least one object in fact makes true every truth is no trivialization of the enterprise. Perhaps it would be a problem if truthmaker theorists were motivated by a single desideratum: giving a truthmaker-any truthmaker-for every truth. But to think this is to once again misread the ambitions of truthmaker theory. Truthmaker theorists aren't happy with just anything as a posited truthmaker. They want truthmakers that are not ad hoc, independently plausible and defensible, and ontologically illuminating. This fact is highly recognizable from the way truthmaker theorists argue. If just finding a truthmaker-any truthmaker-were sufficient, Armstrong's book could have stopped at page 19. That it doesn't reveals that truthmaker theorists do not operate with the understanding of the enterprise that Fine holds. Truthmaker theorists seek after ontological illumination, and insight into what exists. Sure, "the world" is all there is, and might be a truthmaker for all that is true. That we know already. But what are the components of

\footnotetext{
${ }^{5}$ Only in certain cases will propositions themselves be truthmakers: cases of propositions about propositions.

${ }^{6}$ Interestingly, Schaffer (2010) does take this line (as a result of his priority monism), but in so doing he also embraces the conclusion that Fine presumes to be problematic.
} 
the world? What are its individual parts? What sets the world apart from other worlds that could have been? These are core metaphysical questions, and so are of interest to truthmaker theorists, who use their distinctive set of tools to approach and think about them. To suggest that truthmaker theorists care about nothing besides "citing a truthmaker" is the pinnacle of uncharitable interpretation. $^{7}$

\section{Work Still for Truthmaker Theory}

Fine's attempts to refute truthmaker theory rely on various misunderstandings about what the enterprise is, what it hopes to accomplish, and what it is committed to. Once these mistakes are erased, truthmaker theory emerges not as a direct competitor with grounding theory, but an ally. Still, because much of my defense has turned on showing that truthmaker theory does not have the same broad ambitions that grounding theory has, it may be thought that truthmaker theory is of waning interest, and doesn't speak to anything that grounding theory on its own doesn't already cover. This response would be a mistake, however. The central insight that truthmaker theory aims to capture is precisely what grounding theories of the sort Fine advocates are unable to explain.

One of the fundamental ideas that motivates truthmaker theory is that truth depends on reality. The propositions that are true can't be true without the right kind of ontology around to support them. This simple idea provides the basis for the cross-categorial nature of truthmaking, and is the proposed antidote to metaphysical views that commit to various truths without committing to any requisite ontology. (See Armstrong 2004: 1-3.) What is unclear is how Finean grounding theories, on their own, can speak to this basic motivation behind truthmaker theory. In this section I explain why there is theoretical work remaining for truthmaker theory even after the work of grounding is finished.

Grounding claims, on Fine's view, are expressed by connecting various sentences together with a sentential operator. For example: 'Thus it is that the ball is red and that the ball is round that makes it the case that the ball is red and round' (2012: 43). As we saw in the discussion of hierarchies above, grounding claims, in effect, take us from one true proposition to another. Presumably, these chains of truths bottom out in a set of ungrounded claims. Suppose we are offered a completed, exhaustive chart of all the infinitely many truths and how they stand in various grounding relations to one another. What we would have is a comprehensive "book of the world"

\footnotetext{
${ }^{7}$ Williamson makes a similar unwarranted assertion about truthmaker theory (2013: 403), which I critique in Asay 2016.
} 
that showed how all the truths about the world related to one another vis-à-vis what is fundamental and derivative. What we wouldn't have is an ontology. What would be our ontological commitments? Fine's grounding theory doesn't tell us. Consider, for instance, the contentious case of negative existentials. Are they made true by negative facts, absences, or perhaps nothing at all? The question of how we determine what exists on the basis of what is true is precisely what truthmaker theory seeks to answer. Grounding theory always moves from what is true to what is true. Hence, what Finean grounding theory ultimately offers is an alethic structure into which truths are placed. To move from those truths to the ontology underlying them, however, is to engage in truthmaker theory. ${ }^{8}$

As a result, grounding theory (at least in Fine's hands) stays at the "level" of truths; in so doing, it has much to teach us about how the various truths about reality relate to one another, and how some express the nature of that reality in more or less fundamental ways. But truthmaker theorists begin from the idea that truths don't stand alone; they are true in virtue of ontology. Hence, they develop views that answer ontological questions about what there is. This intention to answer the classic ontological question 'What is there?' is what separates truthmaker theory from grounding theory, and provides a paradigm case of a philosophical inquiry that grounding theory-as practiced by Fine-must remain silent on. Hence, rather than revealing truthmaker theory to have nothing to do, grounding theory uncovers precisely the sorts of questions that truthmaker theory is especially suited to explore.

Whether truthmaker theory is an attractive method for studying ontology is of course a controversial issue, and there are plenty of critical remarks one might direct toward the enterprise. Fine's objections, however, fail to engage truthmaker theory as actually developed and practiced, and so deserve no place in the ongoing discussion of its virtues and challenges. There remain other reasons to be interested in truthmaker theory. It enables more careful thinking about the nature of truth, the debates between realism and anti-realism (e.g. Asay 2013), and perennial metaphysical topics such as the reality of the past (e.g. Caplan and Sanson 2011). It even shows up unexpectedly in epistemology: one of Gettier's famous examples turns on the fact that a justified true believer fails to know a given proposition because the fact which provides the believer justification is not the fact that makes the proposition in question true (1963: 122). Though this paper is not the place to explore the various philosophical projects of relevance to truthmaker theory, it is important to point out their existence. For even if truthmaker theory does not, like grounding theory, aim to

\footnotetext{
${ }^{8}$ Furthermore, if one takes some truths to be "ontologically transparent", such that they wear their ontological commitments on their sleeves, then I reply that offering a view as to what those truths are just is engaging in truthmaker theory. For skepticism that any truth wears its ontological commitments on its sleeves, see Azzouni 2007.
} 
offer the complete and exhaustive explanation of metaphysical accounting, it nevertheless has plenty of theoretical relevance. Grounding theorists can turn to truthmaker theory for illumination on these issues; there is no call for antagonism.

\section{Truthmaking and Grounding}

So far I have argued that grounding as pursued by Fine leaves open the very real theoretical task of giving the best account of the ontological grounds for truths. I have also suggested that truthmaking and grounding can cooperate: they are not inherently in competition with one another. In this final section, I offer what I take to be the best way of understanding their relationship.

The largest obstacle to accounting for how truthmaking and grounding relate is the fact that there is no consensus on how either notion should be understood. Furthermore, how the two notions relate is a matter not independent of one's prior theoretical views concerning them. To illustrate, consider Rodriguez-Pereyra's argument for why grounding is not a strict order, i.e. that it does not bear all of transitivity, irreflexivitiy, and asymmetry (2015). ${ }^{9}$ Rodriguez-Pereyra argues that truthmaking is a species of grounding, and that truthmaking possesses none of the logical properties that constitute strict orders. Therefore, grounding is not a strict order. Fine (2012), by contrast, argues that grounding is a strict order, and not cross-categorial. Since truthmaking is not a strict order and is cross-categorial, it is not a species of grounding. Because theories of truthmaking and grounding are still in their relative infancies, this "one person's modus ponens" situation is inevitable. Since I am in no position to presently propound a comprehensive theory of grounding (or meet the objections to it-see, e.g. Wilson 2014), the best I can offer here is some guidance for those who see legitimacy in both truthmaking and grounding, and hope for their reconciliation.

Two basic options are open to reconcilers. It might be that truthmaking and grounding are just different: neither is a species of the other. Their relationship is then simply one of cooperation. Grounding theory provides us the "alethic structure" of the world, revealing how true propositions stand to one another vis-à-vis fundamentality. Truthmaker theory provides the ontological story to supplement the alethic story: truthmaker theory tells us what exists, whereas grounding theory tells us which subject matters are most fundamental. ${ }^{10}$ This is the option I recommend to Fine, given

\footnotetext{
${ }^{9}$ See also Tahko 2013.

10 The idea of truthmaking as a theory of ontological commitment has been explored by Cameron (2008b), Schaffer (2008), and Rettler (2016). While I believe that truthmaker theory does provide answers to the ontological question of
} 
his commitments about the logical structure of grounding that foreclose truthmaking being a species of it.

Alternatively, truthmaking and grounding might stand in a genus/species relationship. Whether this option is more preferable depends, ultimately, on one's further theoretical views about both enterprises. (For example, if one thinks grounding must be a strict order, then this second alternative is closed off.) The choice between them, then, must await a further, more developed theory about both grounding and truthmaking. For present purposes, I shall conclude by considering the second option in more detail.

First, it is far more plausible to suppose that truthmaking is a species of grounding, rather than grounding being a species of truthmaking. ${ }^{11}$ Fine, to his credit, shows what is wrong with the latter option. Taking truthmaking to be a kind of grounding then suggests that grounding should be understood liberally, such that entities of different kinds can enter into it. As a result, views like Fine's, Audi's (2012), and Rosen's (2010) where grounding holds only between sentences or facts are too strict. More appropriate are views like Schaffer's (2009; 2010) where entities of different ontological categories can enter into grounding relationships.

Recall that there is one view that aims to understand truthmaking in terms of grounding that preserves grounding as holding only between truths. That is Cameron's (forthcoming) view that maintains that what it is for $x$ to make $\langle p\rangle$ true is for $\langle p\rangle$ to be grounded by $\langle x$ exists $\rangle$. I find Cameron's approach to be out of spirit with the motivations behind truthmaking. One way of articulating the foundational insight behind truthmaking is that the "alethic" features of our world (i.e. the facts about which truth-values which truth-bearers possess) are not fundamental: the non-alethic features of the world are responsible for the alethic features. But at the bottom of Cameron's hierarchy are true propositions. It is true propositions that are brute, and that provide the metaphysical foundations for all other truths. So construed, Cameron's approach is out of sync with standard thinking about truthmaking (cf. Griffith 2014: 202). For Cameron, the truth of $<$ Socrates exists $>$ is brute and fundamental. For ordinary truthmaker theorists, taking the truth of propositions as brute is precisely what they are trying to avoid. The truth of $<$ Socrates exists $>$ isn't brute: it's grounded by Socrates. For truthmaker theory, bottoming out one's metaphysical hierarchy with truths is a misstep. By subsuming truthmaking into purely propositional grounding, Cameron's view sacrifices the basic instinct behind truthmaker theory.

what exists, whether or not it constitutes a theory of ontological commitment akin to Quine's (1960) or Azzouni's (2004) is a matter I cannot explore presently.

11 Schaffer (2009; 2010), Liggins (2012), Griffith (2014), and Rodriguez-Pereyra (2015) all accept truthmaking as a kind of grounding. 
One implication of Cameron's perspective is that it misunderstands the nature of truthmaker gaps, i.e. truths without truthmakers (be there any). Famously contentious within truthmaker theory is the question of how to handle negative existential propositions, such as <There are no hippogriffs $>$. Some theorists maintain that negative existentials do not have truthmakers (their claims about what doesn't exist are not made true by other entities that do), but that treating them as such is not to concede that they are in any way metaphysically brute, or ultimately inexplicable (e.g. Lewis 2001 and Saenz 2014). Such truthmaker gaps can be treated differently than the truthmaker gaps of, say, Roy Sorensen (2001), who maintains that either the truth-teller ('This sentence is true') or its negation is true, though nothing makes it so. For instance, the truth-values of negative existentials still supervene upon what exists, though the truth-value of the truth-teller (on Sorensen's view) does not. Hence, to accept truths without truthmakers is not necessarily to accept truths as being ultimately metaphysically brute. On Cameron's view, however, claiming a truth to be without a truthmaker is tantamount to saying that it is not grounded by anything, and so is fundamental. Hence, Cameron misinterprets the views of "non-maximalists" such as Lewis and Saenz as treating the truth of $<$ There are no hippogriffs $>$ as being metaphysically brute. Cameron's view does not allow us to distinguish among truthmaker gaps, which is an important theoretical task for truthmaker theory.

I also caution against Griffith's (2014: 204) suggestion as to how to define truthmaking in terms of grounding. For Griffith, to say that $x$ is a truthmaker for $\langle p\rangle$ is to say that $x$ grounds the fact that $\langle p\rangle$ is true. This account preserves the cross-categorial nature of truthmaking: what it is for Socrates to be a truthmaker for $<$ Socrates exists $>$ is for Socrates to provide grounds for an entity Griffith would call 'the fact that <Socrates exists $>$ is true', and that is for grounding to obtain between a fact and a non-fact. The unfortunate consequence of this reduction is that it requires an ontological commitment to facts that otherwise one would have no reason to posit. Normally, facts are postulated within truthmaker theory to be truthmakers, not to be the thing that requires truthmakers. It seems the only to reason to believe in Griffith's extraneous facts is for them to play a role in his proposed reduction.

I suggest, then, that truthmaker theorists who want to connect their views up with grounding accept that truthmaking is a species of grounding, with the result that grounding must admit of cross-categorial cases. That is, any instance of $\langle p\rangle$ being made true by $x$ is an instance of $x$ grounding $\langle p\rangle$. But note that there might be other kinds of grounding that hold between $x$ and $\langle p\rangle$. Consider a view of propositions that takes them to be composed by, dependent upon, or otherwise constituted by the things they are about. In that case, Socrates may play two separate grounding roles with respect to $<$ Socrates exists $>$. Socrates is a truthmaker for $<$ Socrates exists $>$, 
which is to say he provides the ontological grounds for the proposition's being true. But if the existence of the proposition is itself dependent on Socrates, then Socrates provides grounds for the proposition's existence. Hence, Socrates grounds $<$ Socrates exists $>$ in two very different ways. (Griffith, by contrast, sees Socrates as grounding < Socrates exists $>$ in the non-truthmaking case, and Socrates grounding the fact that $<$ Socrates exists $>$ is true in the truthmaking case. I see no reason to favor this view and its ontological additions.)

As for the logical features of grounding, I am generally in agreement with RodriguezPereyra (2015). Truthmaking is not transitive. Socrates is a truthmaker for $<$ There are humans $>$, and $<$ There are humans $>$ is a truthmaker for $<$ There are propositions $>$, but presumably Socrates is not a truthmaker for $<$ There are propositions $>$. Truthmaking is neither irreflexive nor asymmetrical, for $<$ There are propositions $>$ makes itself true. So if truthmaking is a species of grounding, then grounding is not a strict order, contra Fine.

Finally, it's worth stating that even if truthmaking is a species of grounding, it doesn't follow that there is no interest in the independent study of truthmaking. To use the example already illustrated, Socrates might be grounds for $<$ Socrates exists $>$ in at least two different ways. Understanding the general nature of ground won't reveal the differences between the truthmaking that obtains between them, and the composition relations that they instantiate. Griffith insightfully makes the case for this point, and concludes: 'Truthmaking may be a species of grounding, which entails that a definition of truthmaking includes the core notion of grounding, but it is different in many ways from other species. These differences need to be explored in detail' (2014: 213). Hence, even if truthmaking is a species of grounding, it doesn't follow that understanding the general structure of grounding will reveal the specific nature of truthmaking. To the contrary, we need to investigate grounding's specific forms in order to understand what, if anything, ties them all together.

There is no reason to assume any sort of opposition between truthmaking and grounding. Perhaps they are distinct relations that can work together to provide a fuller metaphysical picture of the world than can either individually. Or perhaps they are intimately connected. In that case, certain popular views about the nature of grounding in general are untenable, and it cannot be regimented as strictly as some would prefer. Either way, truthmaking provides insight into the bigger picture of metaphysical grounding, whether as a fellow grounder, or friendly ally. ${ }^{12}$

\footnotetext{
12 Versions of this paper were presented at the University of North Carolina at Chapel Hill in August 2015 and at Yale-NUS College in Singapore in September 2015. My thanks go to the audiences there-and in particular Andrew Bailey, Thomas Hofweber, Neil Mehta, and John Roberts—-for their comments and suggestions. Thanks also go to Sam Baron, Alyssa Ney, Kelly Trogdon, Jack Yip, and the referees for the journal for their helpful feedback and
} 


\section{References}

Aristotle (1995) 'Categories', in T. Irwin and G. Fine (eds. and trans.) Selections, 1-12. Indianapolis: Hackett Publishing Company.

Armstrong, D. M. (1997) A World of States of Affairs. Cambridge: Cambridge University Press.

— (2004) Truth and Truthmakers. Cambridge: Cambridge University Press.

Asay, J. (2013) 'Truthmaking, Metaethics, and Creeping Minimalism', Philosophical Studies 163/1: 213-32.

- (2016) 'Logic and/of Truthmaking', in S. C.-M. Yang, D.-M. Deng, and H. Lin (eds.) Nonclassical Logic, Structural Modelling and Meaning: The Proceedings of the Second Taiwan Philosophical Logic Colloquium TPLC-2014, 37-55. Heidelberg: Springer.

Audi, P. (2012) 'Grounding: Toward a Theory of the In-Virtue-of Relation', Journal of Philosophy 109/12: 685-711.

Azzouni, J. (2004) Deflating Existential Consequence: A Case for Nominalism. Oxford: Oxford University Press.

- (2007) 'Ontological Commitment in the Vernacular', Noûs 41/2: 204-26.

Cameron, R. P. (2008a) 'How to be a Truthmaker Maximalist', Noûs 42/3: 410-21.

- (2008b) 'Truthmakers and Ontological Commitment: or How to Deal with Complex Objects and Mathematical Ontology without Getting into Trouble', Philosophical Studies 140/1: 118.

- (Forthcoming) 'Truthmakers', in M. Glanzberg (ed.) The Oxford Handbook of Truth. Oxford: Oxford University Press.

Caplan, B. and D. Sanson (2011) 'Presentism and Truthmaking', Philosophy Compass 6/3: 196-208. Fine, K. (1994) 'Essence and Modality', Philosophical Perspectives 8: 1-16.

- (2012) 'Guide to Ground', in F. Correia and B. Schnieder (eds.) Metaphysical Grounding: Understanding the Structure of Reality, 37-80. Cambridge: Cambridge University Press.

Fiocco, M. O. (2013) 'An Absolute Principle of Truthmaking', Grazer Philosophische Studien 88: 131.

Gettier, E. L. (1963) 'Is Justified True Belief Knowledge?’, Analysis 23/6: 121-3.

Griffith, A. M. (2014) 'Truthmaking and Grounding’, Inquiry 57/2: 196-215.

Lewis, D. (2001) 'Truthmaking and Difference-Making', Nô̂s 35/4: 602-15.

Liggins, D. (2012) 'Truth-Makers and Dependence', in F. Correia and B. Schnieder (eds.)

discussion. The work described in this paper was substantially supported by a grant from the Research Grants Council of the Hong Kong Special Administrative Region, China (HKU 23400014). 
Metaphysical Grounding: Understanding the Structure of Reality, 254-71. Cambridge: Cambridge University Press.

Lowe, E. J. (2007) 'Truthmaking as Essential Dependence', in J.-M. Monnoyer (ed.) Metaphysics and Truthmakers, 237-59. Frankfurt: Ontos Verlag.

Merricks, T. (2007) Truth and Ontology. Oxford: Clarendon Press.

Milo, R. (1995) 'Contractarian Constructivism’, Journal of Philosophy 92/4: 181-204.

Mulligan, K., P. Simons, and B. Smith (1984) 'Truth-Makers', Philosophy and Phenomenological Research 44/3: 287-321.

Plato (1997) 'Euthyphro', in G.M.A. Grube (trans.), J. M. Cooper (ed.), and D. S. Hutchinson (associate ed.) Complete Works, 2-16. Indianapolis: Hackett Publishing Company.

Quine, W. V. O. (1960) Word and Object. Cambridge: MIT Press.

Restall, G. (1996) 'Truthmakers, Entailment and Necessity', Australasian Journal of Pbilosophy 74/2: $331-40$.

Rettler, B. (2016) 'The General Truthmaker View of Ontological Commitment', Philosophical Studies 173/5: 1405-25.

Rodriguez-Pereyra, G. (2015) 'Grounding is not a Strict Order', Journal of the American Pbilosophical Association 1/3: 517-34.

Rosen, G. (2010) 'Metaphysical Dependence: Grounding and Reduction', in B. Hale and A. Hoffmann (eds.) Modality: Metaphysics, Logic, and Epistemology, 109-35. Oxford: Oxford University Press.

Russell, B. (1918) 'The Philosophy of Logical Atomism', The Monist 28/4: 495-527.

Saenz, N. (2014) 'The World and Truth about What is Not', Philosophical Quarterly 64/254: 82-98.

Schaffer, J. (2008) 'Truthmaker Commitments', Philosophical Studies 141/1: 7-19.

- (2009) 'On What Grounds What', in D. Chalmers, D. Manley, and R. Wasserman (eds.) Metametaphysics: News Essays on the Foundations of Ontology, 347-83. Oxford: Clarendon Press.

- (2010) 'The Least Discerning and Most Promiscuous Truthmaker', Philosophical Quarterly 60/239: 307-24.

Sorensen, R. (2001) Vagueness and Contradiction. Oxford: Clarendon Press.

Tahko, T. E. (2013) 'Truth-Grounding and Transitivity', Thought 2/4: 332-40.

Williamson, T. (2013) Modal Logic as Metaphysics. Oxford: Oxford University Press.

Wilson, J. M. (2014) 'No Work for a Theory of Grounding', Inquiry 57/5-6: 535-79. 